\title{
Diversidade de usos etnobotânicos da flora nativa açoriana. Madeiras, jogos, simbolismo e ornamentação
}

\author{
Diversity of ethnobotanical uses of the azorean native flora. Woods, games, \\ symbolism and ornamentation
}

\section{Diversité des utilisations ethnobotaniques de la flore indigene des açores. Bois, jeux, symbolisme et ornementation}

\author{
Diversidad de usos etnobotanicos de flora nativa de las azores. Maderas, juegos, \\ simbolismos y ornamentación
}

\author{
Mauro Ponte* \\ Eduardo Dias*
}

Recebido em 25/01/2016; revisado e aprovado em 30/03/2016; aceito em 27/04/2016

DOI: http:/ /dx.doi.org/10.20435/1984-042X-2016-v.17-n.4(03)

\begin{abstract}
Resumo: Este estudo teve como finalidade a recolha e sistematização de dados etnobotânicos referentes às relações desenvolvidas entre o povo insular Açoriano e a flora nativa. O método de recolha de informação assentou em dois modelos de entrevistas, a entrevista informal e a entrevista estruturada. Algumas das plantas citadas pelos entrevistados já ostentavam utilizações descritas na literatura. Todavia verificou-se que, em 54 utilizações referidas, distribuídas por 4 classes de uso, 25 são citações novas, das quais sete são atuais e 18 pertencentes a um passado recente, abrangendo um total de 13 espécies.
\end{abstract}

Palavras-chave: etnobotânica; flora; usos.

Abstract: The study was aimed at the collection and systematization of ethnobotanical data on relationships developed between the Azorean islands people and the native flora. The information collection method was based on two models of interviews, i.e., informal interview and a structured interview. Some of the plants mentioned, already bore uses described in literature. However, it was found that of the 54 mentioned uses, distributed by 4 usage classes, 25 are new quotes, of which, 7 are current and 18 belong to a recent past, covering a total of 13 species.

Key words: ethnobotany; flora; uses.

Résumé: L'étude a visé la collecte et la systématisation des données ethnobotaniques sur les relations développées entre les habitants des 'îles des Açores et la flore indigène. La méthode de collecte de l'information a était basée sur deux modèles d'entretiens, à savoir, entretien informel et l'entrevue structurée. Certaines plantes mentionnées, portaient déjà utilisations décrites dans la littérature. Cependant, il a été constaté que, des 54 utilisations citées, distribués par 4 classes d'utilisation, 25 sont de nouvelles citations, dont 7 sont en cours et 18 appartiennent à un passé récent, couvrant un total de 13 espèces.

Mots-clés: ethnobotanique; flora; utilisations.

Resumen: El estudio tuvo como objetivo la recopilación y sistematización de los datos etnobotánicos en las relaciones desarrolladas entre los habitantes de las islas de Azores y la flora nativa. El método de recogida de información se ha basado en dos modelos de entrevistas, es decir, la entrevista informal y una entrevista estructurada. Algunas de las plantas mencionadas, ya llevaban usos descritos en la literatura. Sin embargo, se encontró que, de las 54 utilizaciones mencionadas, distribuidas en 4 clases de uso, 25 son nuevas citas, de las cuales, 7 son actuales y 18 pertenecen a un pasado reciente, que abarca un total de 13 especies.

Palabras clave: etnobotánica; flora; aplicaciones.

* Universidade dos Açores, Angra do Heroísmo, Açores, Portugal. 


\section{INTRODUÇÃO}

O termo etnobotânica foi utilizado, pela primeira vez em 1896, pelo botânico americano William Harshberger (1996), para designar o estudo da relação que surgia entre os seres humanos e as plantas utilizadas por eles. Desde então, a definição dessa ciência tem sido submetida a diversas alterações com o objetivo de encontrar, tal como em outras disciplinas, uma teoria unificadora. Por ser aquela que se considera a mais adequada à natureza da investigação, utilizou-se a definição proposta por Wickens (2001), que define a etnobotânica como uma ciência multidisciplinar que aborda as mútuas relações desenvolvidas entre as culturas humanas e as plantas autóctones, quer no passado, quer no presente (WICKENS, 2001). Na sua definição, Wickens inclui a concepção de Nabhan (1985), segundo a qual as plantas nativas de uma determinada região são aquelas que foram domesticadas em tempos pré-históricos, e que apresentam características morfológicas e fisiológicas adaptadas ao solo e ao clima da região.

O primeiro encontro do ser humano europeu quatrocentista com as ilhas Açorianas desabitadas foi uma surpresa, transmitida, essencialmente, pela forte densidade de cobertura vegetal que as envolvia (DIAS, 2007). A sobre-exploração antropogénica devastou parte significativa desse coberto constituído por um número relativamente limitado de espécies (GASPAR, 1993).

Ao longo de vários anos, muitas pessoas ficaram dependentes dos recursos naturais presentes nas ilhas. Os principais recursos explorados eram as madeiras, com um papel fundamental na construção de casas, reparação naval, alfaias ${ }^{1}$ (grades, arados, timões, cangas e canzis), produção de combustível (lenhas e carvão) e, mais tarde, na construção de móveis (DIAS,

\footnotetext{
${ }^{1}$ Instrumentos e ferramentas rudimentares de apoio às atividades agrícolas.
}

2007). É na floresta que o povo consegue encontrar um pouco de todos os recursos, elementos que são essenciais na construção da paisagem. Provavelmente, por essa razão, o povo açoriano foi construindo símbolos e ícones que ajudaram a perpetuar e a valorizar a cordial relação com a floresta natural (DIAS, 2007). A relação das pessoas com a floresta, como fornecedor de serviços e recursos sustentáveis, é muito forte, no sentido em que expressa o encontro de duas distintas realidades mas inseparáveis, num ciclo que, certamente, ainda não se finalizou. A floresta é talvez, de acordo com Dias (2007), o ecossistema que maior relação cultural estabeleceu com o ser humano, determinando padrões de sociedades e vivências regionais.

Reconheceram-se assim, muitas das potencialidades da vegetação e a utilidade de algumas plantas da floresta. Apesar da reduzida literatura existente, alguns autores (RAMOS, 1871; RIBEIRO, 1964; MARTINS, 1992; FRUTUOSO, 1998; DIAS, 2007) destacam várias plantas com propriedades notáveis, no que diz respeito ao seu emprego na indústria, na agricultura e na arte.

A etnobotânica da flora nativa dos açores é uma área científica que se encontra pouco explorada na região. A carência de estudos dessa natureza é uma realidade, e a reduzida bibliografia demonstra esse mesmo fenómeno. A literatura, normalmente, aborda as relações que ocorrem entre o povo e as plantas num contexto generalizado, e geralmente referente a um passado distante. Porém as descrições e as investigações realizadas não se limitam apenas às espécies naturais. De acordo com os levantamentos e registos bibliográficos assumidos como etnobotânicos, as espécies nativas e exóticas são analisadas e tratadas de igual modo, sendo este aspeto causador da falta de especificidade no que respeita à etnobotânica natural. Desse modo, surge a necessidade de se realizar estudos etnobotânicos direcionados, exclusivamente, à flora natural. 


\section{OBJETIVOS}

O estudo tem como principais objetivos a recolha e a sistematização de informação, em termos gerais, respeitante às relações que surgem entre o povo insular e a flora da vegetação natural dos Açores, quer num passado recente, quer também no presente. Pretende-se, de igual modo, através da sua ordenação, salvaguardar esse saber tradicional, transpondo-o para os tempos atuais, e contribuir, simultaneamente, para o aumento do conhecimento científico que compõe o património etnobotânico da região.

\section{MATERIAL E MÉTODOS}

Para a elaboração de um estudo etnobotânico nos Açores, e perante a carência de trabalhos nessa área científica, foi necessário efetuar uma pesquisa bibliográfica cuidada sobre a teoria da etnobotânica, devido, fundamentalmente, ao cariz multidisciplinar que essa ciência de domínio qualitativo comporta (BALICK; COX, 1996). Foi essencial integrar um conjunto de instrumentos de análise comuns a outras áreas do conhecimento científico como a botânica, ecologia e antropologia.

\subsection{Caraterização dos informantes e área de estudo}

O início da investigação consistiu, em primeiro lugar, na seleção de locais estratégicos, adequados ao desenvolvimento do estudo. O estudo ocorreu na ilha Terceira, com exceção de um caso na ilha do Pico, nas freguesias (Tabela 1) que, num contexto histórico e atual, incluíam pessoas com sistemas de vida que, direta ou indiretamente, estavam relacionados com a utilização de recursos provenientes da floresta natural. Foi igualmente tido em consideração, sempre que possível as freguesias que, devido à sua localização geográfica e aos seus limites administrativos, envolviam pequenos enclaves ou remanescentes de vegetação natural.

Tabela 1 - Lista de freguesias representadas pelos informantes entrevistados.

\begin{tabular}{cc}
\hline Freguesia & Ilha \\
\hline Terra-chã & \\
\hline Conceição & \\
\hline São Mateus & \\
Cinco Ribeiras & Terceira \\
\hline Doze Ribeiras & \\
\hline São Bartolomeu & \\
\hline Posto Santo & \\
\hline Madalena & Pico \\
\hline
\end{tabular}

A localização dos informantes foi realizada através de contactos prévios com trabalhadores da administração local, Igrejas, Juntas de Freguesia, organizações de Solidariedade e desenvolvimento Social quer também por contactos pessoais, tal como refere Carvalho (2006). Foi mantida uma atenção especial relativamente ao surgimento de redes informativas secundárias provenientes de contatos iniciais estabelecidos, sendo estas, por vezes, portadoras de informação potencialmente credível.

Outro critério considerado foi a idade dos informantes, que devia ser $\geq 60$ anos ou, em alguns casos, idade inferior, particularmente, quando a informação lhes tivesse sido transmitida pelos pais, avós ou até mesmo por pessoas idosas mais chegadas. Foram escolhidos, estrategicamente, aqueles que mantinham ou mantiveram uma estreita relação com as características representativas dos sistemas de vida do passado. A investigação deu-se no período compreendido entre maio e julho de 2012. A amostra foi composta por um conjunto de dez informantes, sendo nove de género masculino e uma pessoa do género feminino. A idade mais baixa registada foi de 44 anos, por outro lado, a mais elevada foi de 84 anos. Sete dos entrevistados exercem ou exerceram profissões diretamente relacionadas 
com o uso das plantas (agricultor, jardineiro, carpinteiro, restaurador e pastor), mas também surgem na amostra uma doméstica, um padre e um presidente de junta de freguesia.

\subsection{Coleta de Dados}

O método de recolha de dados assentou, essencialmente, em dois modelos de entrevistas com questões previamente concebidas, nomeadamente, a entrevista informal e, posteriormente, entrevista estruturada. A informação gerada foi registada com auxílio de um gravador multimídia, tendo em atenção a segurança emocional e o conforto do informante em relação ao emprego dessa tecnologia. Caso fossem reveladas perturbações no decorrer da entrevista, relacionadas com a utilização do aparelho, este seria, imediatamente, suspenso prevenindo assim, a perda de qualidade na informação e a rutura da empatia inicialmente estabelecida. Sempre que possível e de acordo com a natureza da comunicação, foram realizadas turnês guiadas pelo campo na companhia do informante com a finalidade de validar os dados cedidos no decurso das entrevistas.

\subsection{Entrevista informal}

A entrevista informal é um processo dinâmico, cujo valor científico dependerá do contexto em que se desenvolve e da perícia do investigador. Desse modo, foram adotadas determinadas regras sociais imprescindíveis, para que a presença do investigador fosse aceite e valorizada pelos locais (ALEXIADES, 1996). O contacto com os informantes principiou com uma breve apresentação pessoal, seguida de uma explicação dos objetivos pretendidos $\mathrm{e}$, finalmente, de que modo o entrevistado poderia ajudar a alcançá-los. Este foi o momento ideal para estabelecer empatia, sendo privilegiada a discussão de temas mais comuns e consensuais, referindo frequentemente e claramente quais os objetivos e as motivações do trabalho. $\mathrm{O}$ investigador estava orientado para uma atitude mais modesta, livre de preconceitos e, simultaneamente, consciente de que o entrevistado era detentor da informação e, como tal, mais sabedor do tema. Contudo, como refere Alexiades (1996), foi mantida uma especial atenção perante assuntos mais sensíveis, estando o investigador consciente da delicada sensatez que separa a curiosidade do respeito pelos assuntos abordados.

\subsection{Entrevista estruturada}

Na preparação da entrevista estruturada, foi elaborado um conjunto de questões filtradas (originadas da entrevista informal), compostas por perguntas diretas e fechadas, fundamentais para o âmbito do estudo. Esse modelo de entrevista permite um maior controle da direção tomada pelo fluxo informativo para que se obtenha uma maior objetividade; daí a sua vulnerabilidade, pois pode permitir a introdução de erros devido ao uso de questões inapropriadas por parte do investigador (CARVALHO, 2006).

\subsection{Questões}

Na sua construção e enunciação, as questões foram desprovidas de elevado grau de complexidade (Tabela 2). Na realização das perguntas, houve o cuidado de não transmitir ao entrevistado, a percepção de que se espera ansiosamente pelas respostas, pois esse grave erro pode levar a que o entrevistado, por impulso, forneça informações distorcidas ou até mesmo erradas sobre a natureza das utilizações (BERNARD, 1988; ALEXIADES, 1996). 
Tabela 2 - Exemplos de questões colocadas aos informantes, consoante a tipologia de entrevista aplicada. Adaptado de Mendiola (2005) e Carvalho (2006).

Tipos de questões estabelecidas para entrevista informal
Tipos de questões estabelecidas para entrevista estruturada

\begin{tabular}{|c|c|}
\hline $\begin{array}{l}\text { Que plantas utiliza na sua alimentação, ou } \\
\text { que tenha utilizado? }\end{array}$ & Época de recolha? \\
\hline $\begin{array}{l}\text { Já colheu frutos ou plantas da floresta } \\
\text { natural? }\end{array}$ & Quantidade recolhida? \\
\hline $\begin{array}{l}\text { Recorda-se de algum remédio tradicional } \\
\text { para a saúde? }\end{array}$ & Como reconhece a planta? \\
\hline Utiliza algum? & Como se conserva após a colheita? \\
\hline $\begin{array}{l}\text { Conhece algum conto ou historia, } \\
\text { relacionado com as plantas? }\end{array}$ & Quais os seus nomes vernáculos? \\
\hline $\begin{array}{l}\text { Recorda-se de alguma brincadeira, jogos de } \\
\text { crianças/adultos, que envolva plantas? }\end{array}$ & Quem, quando, onde recolhe? \\
\hline $\begin{array}{l}\text { Já preparou bebidas derivadas de plantas da } \\
\text { floresta natural? }\end{array}$ & $\begin{array}{l}\text { Uso tradicional, quem utiliza, como se } \\
\text { utiliza, onde se utiliza? }\end{array}$ \\
\hline $\begin{array}{l}\text { Lembra-se de como ou de que materiais se } \\
\text { construíam as habitações no passado? }\end{array}$ & \multirow{2}{*}{$\begin{array}{l}\text { Se a planta é uma cultivar existe algum } \\
\text { protocolo para o seu cultivo e colheita (hora } \\
\text { do dia, ciclo lunar, estação doano)? }\end{array}$} \\
\hline $\begin{array}{l}\text { Que outro tipo de utilização material dava } \\
\text { as plantas? }\end{array}$ & \\
\hline $\begin{array}{l}\text { Que plantas utilizava ou utiliza para } \\
\text { alimentar os animais da quinta ou } \\
\text { domésticos? }\end{array}$ & \multirow{2}{*}{$\begin{array}{l}\text { No uso medicinal, órgão da planta } \\
\text { empregado, quantidadeutilizada, } \\
\text { processamento, armazenamento, doença } \\
\text { tratada/efeitos, administração (interna, } \\
\text { externa etc.), terapias complementares, nome } \\
\text { local da doença, outros aspetos? }\end{array}$} \\
\hline $\begin{array}{l}\text { Que tipo de combustível utilizava em sua } \\
\text { casa? }\end{array}$ & \\
\hline
\end{tabular}

As questões colocadas não poderiam conter, de forma direta ou indireta, a própria resposta, pois essa ação, provavelmente, conduziria o informante a confirmar e a determinar a hipótese, viciando e inquinando os resultados da entrevista. Durante as repostas fornecidas, o informante nunca foi interrompido, pois como Whyte (1982) refere, supõe-se que a intermissão é uma manifestação de impaciência latente e, portanto, uma circunstância jamais justificável numa entrevista de cariz etnobotânico.

Por último, no decorrer das entrevistas, o investigador não manifestou a sua desaprovação ou qualquer outro tipo de julgamento perante o informante ou pela informação fornecida. Essa situação foi, particularmente, adequada, pois é comum verificar-se, nas áreas rurais, a convicção de que a cultura urbana e os seus representantes questionam as tradições rurais com um elevado número de preconceitos (ALEXIADES, 1996).

\subsection{Organização dos dados}

Os dados que apresentaram utilizações não descritas na literatura investigada foram assumidos como novos usos e organizados sob dois aspetos do contexto temporal, ou seja, os atuais e os que se referem a um passado recente. Foram consideradas utilizações atuais, aquelas que ainda eram exercidas pelo informante ou as que praticou no seu passado. Os dados relativos ao passado recente correspondem àqueles que foram citados pelos entrevistados ou transmitidos por seus ascendentes, mas que não apresentam utilizações 
atuais. Optou-se por ordenar as plantas utilizadas e mencionadas pelos entrevistados em quatro classes de uso: Madeira; Jogos; Simbolismo e Ornamentação. Essa escolha centraliza-se, essencialmente, no caráter análogo que as diversas utilizações demonstraram possuir.

\section{RESULTADOS E DISCUSSÃO}

Das entrevistas realizadas, contabilizou-se um total 54 utilizações (Tabela 3) distribuídas por quatro classes de uso. A classe das Madeiras com $67 \%$ das referências destaca-se, substancialmente, das outras etnocategorias. Seguida, com $13 \%$ das utilizações, surge o grupo dos Símbolos e, finalmente, os dois restantes grupos, ambos, com $10 \%$ das citações (Figura1).

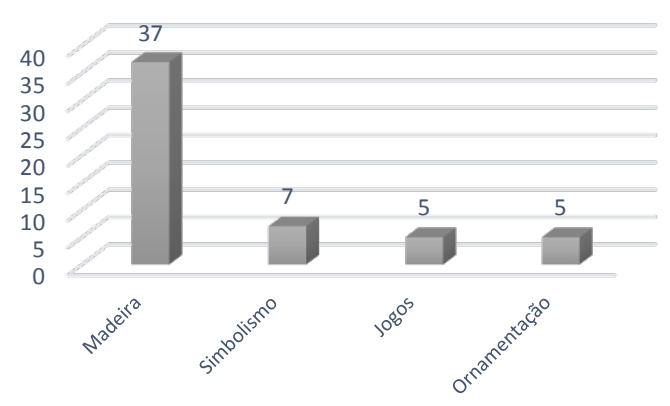

Figura 1 - Total de utilizações citadas pelos entrevistados, distribuídas por 4 classes de uso.

Tabela 3 - Utilizações etnobotânicas citadas pelos informantes, no decorrer das entrevistas, de plantas pertencentes à flora natural dos Açores. Os nomes científicos das espécies estão de acordo com a lista de referência realizada por Dias et al. (2010).

\begin{tabular}{|c|c|c|c|c|}
\hline Informantes & Espécie & Nome comum & Órgão da planta & Utilizações \\
\hline \multirow{3}{*}{ A } & $\begin{array}{l}\text { Juniperus brevifolia (Seub.) } \\
\text { Antoine. }\end{array}$ & Cedro-do-mato & Tronco e ramos & $\begin{array}{l}\text { Braços de Violas; Restauro de } \\
\text { cadeiras e mesas; Cavernas de barcos }\end{array}$ \\
\hline & Picconia azorica (Tutin) Knobl. & Pau-branco & Troncos e ramos & $\begin{array}{l}\text { Grades de arados; Timões; Maços de } \\
\text { madeira }\end{array}$ \\
\hline & Laurus azorica (Seub.) Franco. & Loureiro & Troncos e ramos & Timões; Cangas \\
\hline \multirow{7}{*}{ B } & $\begin{array}{l}\text { Juniperus brevifolia (Seub.) } \\
\text { Antoine. }\end{array}$ & Cedro-do-mato & $\begin{array}{l}\text { Tronco, restos de } \\
\text { madeira }\end{array}$ & $\begin{array}{l}\text { Estrutura dos telhados (tirantes); } \\
\text { Carrocinhas }\end{array}$ \\
\hline & Picconia azorica (Tutin) Knobl. & Pau-branco & Ramos & Piões \\
\hline & Morella faya Ait & Faia-da-terra & Tronco & Estrutura dos telhados (tirantes). \\
\hline & Dracaena draco (L.) $L$. & Dragoeiro & Seiva da planta & $\begin{array}{l}\text { Arte pictórica; Símbolo de estatuto } \\
\text { social }\end{array}$ \\
\hline & Hedera azorica Carr. & Hera & Planta e folhas & $\begin{array}{l}\text { Símbolo de longevidade e fidelidade; } \\
\text { Ornamentação e decoração }\end{array}$ \\
\hline & Angelica spp. & Angélica & Planta & Citada na bíblia \\
\hline & $\begin{array}{l}\text { Polypodium azoricum } \\
\text { (Vasconcellos) R. Fern. }\end{array}$ & Polipódio & Frondes & $\begin{array}{l}\text { Crenças terapêuticas de } \\
\text { desintoxicação }\end{array}$ \\
\hline \multirow{3}{*}{$\mathrm{C}$} & Morella faya Ait. & Faia-da-terra & Ramos & Brincadeiras de criança \\
\hline & Hedera azorica Carr. & Hera & Folhas e umbelas & Decoração e ornamentação \\
\hline & Laurus azorica (Seub.) Franco & Loureiro & Ramos e folhas & $\begin{array}{l}\text { Decoração na época natalícia; } \\
\text { Combustível }\end{array}$ \\
\hline \multirow{2}{*}{$\mathrm{D}$} & Calluna vulgaris (L.) Hull & Queiró & Tronco e ramos & Combustível (lenha) \\
\hline & Erica azorica Hochst. & Vassoura & Tronco e ramos & Combustível (lenha) \\
\hline \multirow{5}{*}{$\mathrm{E}$} & Picconia azorica (Tutin) Knobl. & Pau-branco & Tronco e ramos & $\begin{array}{l}\text { Construção de habitações; Eixo do } \\
\text { carro de bois; Atafonas; Fabrico de } \\
\text { móveis }\end{array}$ \\
\hline & $\begin{array}{l}\text { Juniperus brevifolia (Seub.) } \\
\text { Antoine }\end{array}$ & Cedro-do-mato & Tronco e ramos & $\begin{array}{l}\text { Estrutura de suporte dos tetos; Pipas } \\
\text { de vinho; Potes de vinho; Calçado } \\
\text { (galochas); Móveis; Carvão }\end{array}$ \\
\hline & Morella faya Ait. & Faia-da-terra & Tronco e ramos & Estrutura de suporte dos tetos. \\
\hline & Frangula azorica V. Grubow & Sanguinho & Tronco e ramos & $\begin{array}{l}\text { Peças de mobiliário; Torneados; } \\
\text { Cangas; Alfaias }\end{array}$ \\
\hline & Espécies arbóreas naturais & $\begin{array}{l}\text { Espécies plantadas em } \\
\text { vértices de campos } \\
\text { agrícolas }\end{array}$ & Todos os órgãos & Alfaias \\
\hline
\end{tabular}




\begin{tabular}{|c|c|c|c|c|}
\hline Informantes & Espécie & Nome comum & Órgão da planta & Utilizações \\
\hline \multirow{5}{*}{$\mathrm{F}$} & $\begin{array}{l}\text { Juniperus brevifolia (Seub.) } \\
\text { Antoine }\end{array}$ & Cedro-do-mato & Tronco e Ramos & Oratório; Galochas \\
\hline & $\begin{array}{l}\text { Laurus azorica (Seub.) Franco } \\
\text { azorica }\end{array}$ & Louro & Ramos & Combustível (lenha) \\
\hline & Erica azorica Hochst. & Urze & Tronco e ramos & Combustível (lenha) \\
\hline & $\begin{array}{l}\text { Daucus azoricus (Franco) Rivas } \\
\text { Mart., Lousã, Fern. Prieto, E. } \\
\text { Días, J.C. Costa \& C. Aguiar }\end{array}$ & Cenoura-burra & $\begin{array}{l}\text { Caule, folhas e } \\
\text { Inflorescências }\end{array}$ & $\begin{array}{l}\text { Ornamentação (arranjos florais em } \\
\text { jarras) }\end{array}$ \\
\hline & Umbilicus spp. & Coucelos & Folhas & Brincadeiras de Crianças \\
\hline \multirow{7}{*}{ G } & $\begin{array}{l}\text { Juniperus brevifolia (Seub.) } \\
\text { Antoine }\end{array}$ & Cedro-do-mato & Tronco e ramos & Galochas; Pipas e jarros vinho \\
\hline & Calluna vulgaris (L.) Hull & Rapa & Tronco e ramos & Combustível (lenha) \\
\hline & Erica azorica Hochst. & Vassoura & Tronco & Carvão \\
\hline & Laurus azorica (Seub.) Franco & Louro & Tronco e ramos & Alfaias agrícolas. \\
\hline & Morella faya Ait. & Faia-da-terra & Tronco & Construção de tetos \\
\hline & Frangula azorica $V$. Grubow & Sanguinho & Tronco e ramos & Alfaias agrícolas \\
\hline & $\begin{array}{l}\text { Área natural dos mistérios } \\
\text { negros }\end{array}$ & & & $\begin{array}{l}\text { Antigo curral, com história religiosa } \\
\text { associada }\end{array}$ \\
\hline \multirow{5}{*}{$\mathrm{H}$} & Laurus azorica (Seub.) Franco & Louro & Ramos & Cabos para utensílios agrícolas \\
\hline & $\begin{array}{l}\text { Juniperus brevifolia (Seub.) } \\
\text { Antoine }\end{array}$ & Cedro-do-mato & Tronco e ramos & $\begin{array}{l}\text { Galochas; Cadeiras; Alfaias } \\
\text { agrícolas; Potes; Selhas; Baldes e } \\
\text { Lenha }\end{array}$ \\
\hline & Picconia azorica (Tutin) Knobl. & Pau-branco & Troncos & Bola do tradicional jogo do Emboca. \\
\hline & Morella faya Ait. & Faia-da-terra & Planta & Sebes (abrigos) \\
\hline & Erica azorica Hochst. & Urze & Troncos e ramos & $\begin{array}{l}\text { Lenha; Tinchão (suporte em formato } \\
\text { de forquilha utilizado para elevar as } \\
\text { videiras do solo); Carvão }\end{array}$ \\
\hline \multirow{6}{*}{ I } & Laurus azorica (Seub.) Franco & Louro & Raiz & Carvão \\
\hline & Ilex azorica Gandoger & Azevinho & Ramos e folhas & Lenha \\
\hline & $\begin{array}{l}\text { Juniperus brevifolia (Seub.) } \\
\text { Antoine }\end{array}$ & Cedro-do-mato & Tronco e ramos & $\begin{array}{l}\text { Cavernas; Galochas; Potes; Pipas de } \\
\text { vinho; Selhas; Banheiras; } \\
\text { Recipientes para o gado beber água }\end{array}$ \\
\hline & Picconia azorica (Tutin) Knobl. & Pau-branco & Ramos & Canzis \\
\hline & Erica azorica Hochst. & Urze & Troncos e ramos & Canzis; Carvão para os ferreiros \\
\hline & Hypericum foliosum Ait. & Maltrage ou Maltraje & Planta & Símbolo de maldição \\
\hline \multirow[t]{6}{*}{$\mathrm{J}$} & Frangula azorica V. Grubow. & Sanguinho & Ramos & Bucheiros (Pesca); Cantadeiras \\
\hline & $\begin{array}{l}\text { Juniperus brevifolia (Seub.) } \\
\text { Antoine. }\end{array}$ & Cedro-do-mato & Troncos e ramos & Galochas; Cavernas; Miniaturas \\
\hline & Picconia azorica (Tutin) Knobl. & Pau-branco & Troncos & Fuso (Lagar) \\
\hline & Morella faya Ait. & Faia-da-terra & Troncos e ramos & Tirantes; Traves (tetos) \\
\hline & Viburnum treleasei Gand. & Folhado & Casca & $\begin{array}{l}\text { Tingimento de armadilhas de pesca } \\
\text { para as camuflar; Fabrico de } \\
\text { chalupas (pequeno barco à vela) }\end{array}$ \\
\hline & Laurus azorica (Seub.) Franco. & Loureiro & Planta $\mathrm{S}$ / raízes & Festejos de São João \\
\hline
\end{tabular}

No decorrer das entrevistas, foram citadas pelos informantes 13 espécies vegetais com usos não referidos nas principais e pertinentes referências bibliográficas analisadas. A classe das Madeiras é aquela que possui mais referências, somando $44 \%$ das utilizações, sendo a espécie Juniperus brevifolia a mais citada com três usos. A Piconia azorica, junto com a Frangula azorica, são as menos referidas do grupo, ambas com uma aplicação apenas. As restantes espécies apresentam dois empregos cada uma. Seguidamente, com $28 \%$, surge a classe dos Símbolos, em que a espécie Hypericum foliosum se destaca ligeiramente das restantes, com 2 utilizações. As outras duas categorias, ou seja, Jogos e Ornamentação, representam, respetivamente, $16 \%$ e $12 \%$ das aplicações, enquanto todas as espécies dispõem apenas de uma aplicação.

No contexto temporal, foram identificadas 7 utilizações atuais, sendo a espécie Laurus azorica a mais citada com duas utilizações, seguindo-se as restantes plantas apenas com uma aplicação cada uma. Foram registadas ainda 18 utilizações pertencentes a um passado recente destacando-se, significativamente, do valor assinalado para os usos atuais. A espécie Juniperus brevifolia aparece em primeiro lugar com três referências. Seguidamente, surgem três espécies, nomeadamente, a Piconia azorica, Laurus azorica e Viburnum treleasei. Finalmente, e com apenas uma referência, ocorrem as restantes espécies. 
Tabela 4 - Classes de usos citados pelos entrevistados em dois contextos temporais e que não se encontram referenciados na literatura.

\begin{tabular}{|c|c|c|c|c|c|c|c|c|}
\hline \multirow[b]{2}{*}{ Espécies } & \multirow[b]{2}{*}{ Madeira } & \multirow[b]{2}{*}{ Símbolos } & \multirow[b]{2}{*}{ Jogos } & \multirow[b]{2}{*}{ Ornamentação } & \multicolumn{3}{|c|}{ Contexto Temporal } & \\
\hline & & & & & Utilizações Atuais & & $\begin{array}{c}\text { Utilizações Passadas } \\
\text { recentes }\end{array}$ & \\
\hline Juniperusbrevifolia & 3 & & 1 & & $\begin{array}{l}\text { Miniaturas em } \\
\text { madeira }\end{array}$ & 1 & $\begin{array}{c}\text { Braços de viola; Oratório; } \\
\text { Carrocinhas }\end{array}$ & 3 \\
\hline Piconia Azorica & 1 & & 1 & & & & Bola emboca; Pião & 2 \\
\hline Laurus azorica & 2 & 1 & & 1 & $\begin{array}{l}\text { Paus para espetadas; } \\
\text { Festejos São João }\end{array}$ & 2 & $\begin{array}{l}\text { Carvão a partir das raízes; } \\
\text { Decoração época natalícia }\end{array}$ & 2 \\
\hline Frangulaazorica & 1 & & & & & & Elaboração de bucheiros & 1 \\
\hline Erica azorica & 2 & & & & Tinchão & 1 & Chamuscar suínos & 1 \\
\hline Viburnum treleasei & 2 & & & & & & Chalupa; Fertilizante & 2 \\
\hline Dracaena draco & & 1 & & & & & Estatuto social & 1 \\
\hline Hedera azorica & & 1 & & 1 & Decoração & 1 & Longevidade e fidelidade & 1 \\
\hline $\begin{array}{l}\text { Polypodium } \\
\text { azoricum }\end{array}$ & & 1 & & & & & $\begin{array}{l}\text { Crença terapêutica } \\
\text { (desintoxicação) }\end{array}$ & 1 \\
\hline Hypericumfoliosum & & 2 & & & $\begin{array}{l}\text { Nova designação } \\
\text { para nome comum }\end{array}$ & 1 & Maldição & 1 \\
\hline $\begin{array}{l}\text { Área natural dos } \\
\text { mistérios negros }\end{array}$ & & 1 & & & & & Culto Espírito Santo & 1 \\
\hline Morella faya & & & 1 & & & & Bonecas & 1 \\
\hline Umbilicus spp. & & & 1 & & & & Desenhos ornamentais & 1 \\
\hline Daucus azoricus & & & & 1 & $\begin{array}{c}\text { Decoração } \\
\text { (Habitações, igrejas) }\end{array}$ & 1 & & \\
\hline Total & 11 & 7 & 4 & 3 & & 7 & & 8 \\
\hline
\end{tabular}

Os informantes inseridos nas dinâmicas urbanas demonstraram-se, tendencionalmente, "contaminados" pelo saber académico. Esse aspeto foi colocado em particular evidência pelos próprios entrevistados no decorrer das entrevistas, nomeadamente, através de constantes citações bibliográficas ou de comentários suportados pela informação disponível na internet.

Por outro lado, os informantes enquadrados nos sistemas de vida rurais foram aqueles que se apresentaram menos influenciados pelo conhecimento acadêmico. Em boa verdade, confirma-se que é, nessa esfera, que podemos encontrar potenciais amostras da tipologia da informação que se pretende no âmbito da etnobotânica.

\section{MADEIRAS}

Segundo os informantes, as espécies lenhosas (arbóreas e arbustivas) eram aquelas que detinham mais utilizações no passado devido, em parte, à boa qualidade que as madeiras dessas espécies apresentavam, mas também, por serem recursos naturais que estariam mais disponíveis às populações locais. Atualmente, o uso dessas madeiras, e de acordo com os dados provenientes dessa amostragem, é praticamente inexistente, exceto raras exceções, como veremos adiante.

A espécie Juniperus brevifolia, no passado era usada para fabricar braços de violas, cavernas de barcos, armação dos telhados, carvão, oratórios, janelas, 
selhas ${ }^{2}$, baldes, banheiras, alfaias, lenha e galochas ${ }^{3}$. Essa madeira também servia para restaurar mobiliário como arcas, mesas e cadeiras, sendo, igualmente, utilizada na indústria vitivinícola, nomeadamente, na elaboração de pipas, potes e jarros de vinho. Destaca-se uma utilização recente relacionada com o emprego da sua madeira, tendo-se verificado que uma das pessoas entrevistadas dispõe de uma impressionante coleção de miniaturas que replicam detalhadamente alfaias e instrumentos agrícolas tradicionais. O reconhecimento deste trabalho está representado e inserido no roteiro turístico artesanal da freguesia de Santo Amaro na Ilha do Pico.

A madeira da Picconia azorica era utilizada no passado para construir alfaias agrícolas, atafonas, fusos de lagar, móveis, peças de carros de bois e alguns aspetos da construção de residências. Porém essa planta ostentava um emprego particularmente interessante, isto é, servia para fabricar a bola do tradicional jogo do emboca, praticado na Ilha Terceira. Atualmente, essa espécie ocorre com pouca abundância na ilha, e por essa razão, a matéria-prima usada para fabricar o esférico foi substituída pela madeira do Metrosidero excelsa, que é uma espécie introduzida e naturalizada.

No passado recorria-se à madeira de Laurus azorica para fabricar alfaias como, por exemplo, os arados, os timões e as cangas, sendo, igualmente, uma planta muito boa para produzir cabos de utensílios agrícolas, sobretudo, devido à suavidade que a madeira exibe. Esta servia também para produzir carvão, mas apenas a partir das suas raízes. Outra utilização era a elaboração da cantadeira dos antigos carros de bois, que originava o tradicional e característico chiar que esses carros emitiam. De acordo com as entrevistas efetuadas, foi

\footnotetext{
${ }^{2}$ Vaso de madeira em formato circular com as bordas baixas.

3 Calçado (o mesmo que tamancos) rudimentar elaborado a partir de madeira.
}

identificada apenas uma utilização atual: os ramos, fortemente aromáticos, que constituem essa planta são usados para fazer espetos nos churrascos, atribuindo um sabor particularmente distinto à comida.

A madeira da espécie Morella faya, conhecida vulgarmente por Faia-da-terra, era, segundo os entrevistados, utilizada apenas para elaborar a estrutura de suporte dos tetos que compõem as habitações, mais precisamente, no fabrico de tirantes ${ }^{4}$.

A Frangula azorica, vernaculamente designada por Sanguinho, exibia um uso semelhante ao do Louro, sendo igualmente usada para criar a cantadeira do antigo carro de bois. No entanto, ainda surgem outros usos associados como, por exemplo, o fabrico de algumas alfaias, cabos de bucheiros (pesca), peças de mobiliário e torneados.

A madeira derivada das espécies Calluna vulgaris e Erica azorica servia para alimentar energeticamente os antigos fornos, principalmente, através da sua lenha, mas também por meio de carvão previamente elaborado. Os ramos dessas espécies, junto com a sua folhagem, depois de incendiados, eram utilizados para chamuscar os pelos do corpo de suínos na tradicional matança.

Com pequenos ramos, provenientes dessas espécies, em formato de forquilha, constrói-se um suporte que se dá pelo nome de tinchão e que serve, essencialmente, para manter as videiras mais elevadas do solo, proporcionando à planta uma eficaz ventilação sendo um processo determinante para garantir a redução de fungos patogênicos. A utilização deste artefacto implica, simultaneamente, um melhoramento da incidência luminosa sobre cachos de uvas. Esse processo permite, em conjugação com a natureza basáltica das rochas locais, um adequado amadurecimento dos frutos, conferindo-lhes um sabor discriminadamente único.

\footnotetext{
4 Viga comprida em madeira que serve para suportar o telhado de habitações rurais tradicionais.
} 
De todas as utilizações referidas no que respeita ao emprego da madeira, destaca-se uma, carateristicamente curiosa, ou seja, o emprego do tronco da espécie arbustiva Viburnum treleasei na construção de uma chalupa (embarcação à vela de reduzidas dimensões), que perpetua ainda na atualidade em posse de um privado. Segundo o informante, o tronco media, aproximadamente $0,7 \mathrm{~m}$ de diâmetro e podia variar entre os $4 \mathrm{~m}$ e $5 \mathrm{~m}$ de altura, mais adianta que a planta gerava elevada impressão perante os locais, devido à sua sensacional dimensão.

Uma causa apontada pelo informante e que podia estar na origem desse crescimento anormal seriam os estímulos provocados pelas insistentes podas efetuadas à copa que, posteriormente, serviam como fertilizante ou combustível. Nos Açores, essa espécie de arbusto está associada a manchas de vegetação natural (florestas laurifólias e matos colonizadores), onde não é comum observar-se indivíduos com porte acima dos $2 \mathrm{~m}$ de altura e com o diâmetro de tronco superior a $0,2 \mathrm{~m}$; contudo Shäfer (2005) refere que esses indivíduos, em condições ambientais favoráveis, poderão atingir os $4 \mathrm{~m}$. Apesar de atualmente não se verificarem no campo indivíduos com a dimensão apontada pelo informante, não podemos negligenciar a possibilidade de ter ocorrido no passado plantas dessa espécie com características fenotípicas distintas.

As pessoas entrevistadas demonstraram que praticamente todas essas plantas, no que diz respeito à utilização de madeiras, tinham igual uso no passado, sendo já descritas por diversos autores ao longo dos tempos. Dessa forma, obtemos mais corroborações que acrescentam e fortalecem o conhecimento da relação desenvolvida entre o povo insular e os recursos disponibilizados pela flora nativa. Nota-se que esse conhecimento progrediu ao longo dos tempos, até aos dias de hoje, através de várias gerações, e, por essa razão, é lógico ponderar, especialmente quando correlacionamos essa informação com a literatura antiga (e.g. quinhentista), que existe uma considerável concordância com os dados cedidos pelos representantes desta amostra.

Atualmente, o emprego dessas madeiras é praticamente inexistente, salvo os raros casos anteriormente enumerados. Essa circunstância parece estar fortemente relacionada com a reduzida quantidade que essas espécies vegetais exibem na região, situação que, por um lado, evoluiu da intensa e desajustada exploração que se deu no passado e, por outro lado, da progressiva alteração do uso do solo através da implementação de sistemas de produção agrícola e florestal, enquanto se verificava em simultâneo o desenvolvimento dos diversos núcleos urbanos, tal como refere Dias (2007). Outros fatores importantes que influenciaram possivelmente a redução dessas utilizações foi a chegada das novas tecnologias à região (combustíveis, técnicas atuais de construção, mecanização etc.), bem como o surgimento de instrumentos de regulação legal que deram origem a estatutos de proteção e a várias medidas de conservação (DIAS, 2007).

\section{JOGOS}

Foram identificadas cinco espécies de plantas associadas à flora natural que eram utilizadas em brincadeiras ou para produzir brinquedos. Os ramos de maior diâmetro pertencentes à espécie Picconia azorica serviam para fazer piões que eram utilizados em jogos pelas crianças. Essa planta também tinha uma aplicação bastante peculiar, a madeira era usada para fabricar as bolas do tradicional e quase extinto jogo do Emboca. Os carpinteiros, a pedido dos jogadores, coletavam essa madeira e, nas suas oficinas, talhavam os troncos mais largos até atingirem uma forma esférica. Esse jogo foi bastante praticado (na freguesia das Doze Ribeiras) até a um passado bem recente, tendo perdido 
o seu costume devido ao envelhecimento dos jogadores e, simultaneamente, ao desinteresse das gerações mais novas.

Os carpinteiros, após o emprego da madeira proveniente do Juniperus brevifolia nas mais diversas aplicações, reciclavam o material restante (reduzidas réstias de madeira) construindo carrocinhas que posteriormente eram vendidas ou oferecidas. Essas carroças que se destinavam às crianças, serviam não só para entretê-las mas também para as sensibilizar para a vida do campo.

Os ramos da Morella faya, segundo o informante $C$, eram utilizados para simular meninas que, levadas pela mão, iam para escola. As bonecas eram elaboradas a partir de um conjunto de ramos invertidos que seriam as "saias"; a cabeça era formada no ápice do ramo mais largo por um agrupado de panos amarrados com um cordel.

As crianças usavam a página inferior das folhas pertencentes às plantas herbáceas do género Umbilicus (Coucelos) para desenhar. Com recurso a um fino e aguçado ramo qualquer, picotavam as folhas até esboçarem o desenho pretendido e, de seguida, em tom de partilha, trocavam os desenhos entre si. Esta é uma evidência de como as crianças, em grupo, podiam desenvolver interações e aptidões sociais numa época marcada pela elevada dificuldade que comportava a vida rural.

\section{SIMBOLISMO}

De acordo com os entrevistados, algumas plantas revelaram possuir simbologias, crenças e até superstições associadas ao imaginário do povo local. Foram identificadas 7 plantas que transmitem, na esfera emotiva, relações que procuram dar uma explicação racional através de símbolos, crenças e superstições que quebram as barreiras do real, gerando, no plano imaterial, um riquíssimo património imaginativo. A valorização dessa dimensão passa em primeiro lugar pelo seu registo e, de seguida, pela sua transmissão às gerações vindouras perpetuando assim, o valor não só físico, mas também imaterial da flora da região. De facto, a maioria dos contos, lendas, crenças, mitos e superstições, acabam por estar, de forma direta ou indireta, ligadas às plantas, por exemplo, da floresta. Um claro exemplo desse fenómeno são os contos produzidos pela grande indústria cinematográfica da Walt Disney.

A planta conhecida vulgarmente por Dragoeiro (Dracaena draco), segundo um dos informantes, era simbólica de um determinado status social, fundamentalmente, por estar associado a uma riqueza rural e urbana. Na realidade, quem fosse proprietário de alguns indivíduos dessa espécie sabia, desde logo, que estava na posse de uma riqueza, mais que não seja a venda da sua seiva para as diversas indústrias como, por exemplo, a tinturaria ou arte pictórica.

O gênero Angelica, de acordo com o informante B, vem referenciado na Bíblia, e terá sido o arcanjo Rafael e/ou Miguel (existe alguma dificuldade na identificação do arcanjo) quem deu a conhecer ao ser humano as suas virtudes, que foram enaltecidas pelos antigos e consideradas outrora miraculosas. Segundo essa crença, a Angelica era recomendada pelo informante (padre) para afastar a peste, neutralizar o efeito de venenos e prolongar a vida do indivíduo. Vale a pena ressaltar que Cameron (1883), Mac Coitir e Langrishe (2006) referem, nas suas obras, utilizações tradicionais idênticas na cultura escocesa e irlandesa.

A Hedera azorica era uma planta que estava conectada ao povo através de uma relação imaterial benigna. $O$ povo terceirense atribui-lhe qualidades simbólicas como a longevidade e a fidelidade. Essa interação parece advir de uma ligação de proximidade que existia entre ambos (planta e povo). A mútua convivência permitiu que o povo tomasse conhecimento do prolongado ciclo biológico que a planta 
possui, portanto, essa particularidade que era entendida como um bom presságio acabou por ser associada mais tarde ao conceito de fidelidade.

Antigamente, o povo dispunha sobre o abdómen dos bebés, frondes da espécie Polypodium azoricum, manifestando uma convicção ou crença de que os parasitas intestinais seriam expulsos do organismo. Contudo as pessoas tiveram que basear essa crença em algum pressuposto, e, como refere o informante $\mathrm{B}$, as substâncias aromáticas volatizantes poderiam, de algum modo, estar relacionadas com essa aplicação.

A planta da espécie Hypericum foliosum (Maltrage ou Maltraje) apresentava uma curiosa superstição. No passado, os indivíduos que recolhiam madeiras da floresta, sempre que enchiam o carro-de-bois com madeira proveniente dessa planta, este acabava por tombar e, por essa razão, diziam que a madeira estava amaldiçoada. Segundo relatos na ilha do Pico, essa planta também é conhecida vulgarmente por Malfurada ou Chocalhos-dodiabo sendo, frequentemente, associada a poderes ocultos malignos. Se dividirmos a palavra em duas, assumindo que o nome comum dessa planta é Maltraje, obtemos, Mal e Traje. Traje, significa roupa, vestuário ou simplesmente o ato de vestir, contudo alguns dicionários referem que essa palavra, em determinadas circunstâncias, pode significar disfarce, sobretudo, em épocas de festividades como o Carnaval. Hipoteticamente, esse nome poderá significar "Mal disfarçado", no entanto ficam ainda por efetuar estudos de cariz etimológico para confirmar a lenda.

No dia de São João, era comum colher uma copa inteira da espécie arborescente Laurus azorica, junto com o seu tronco, embora cortado, mas o suficiente para se destacar da copa. O caule era fixado ao solo para que a copa se mantivesse estavelmente ereta, sendo de seguida preenchida nos espaços vazios, que surgem entre a ramagem, com gramíneas (palha) secas. Posteriormente, a copa era incendiada dando origem a uma fogueira de considerável dimensão, que tinha como intuito a celebração do santo popular. A copa ostenta a particularidade notável, de, no ato da queima, a madeira do Loureiro emitir estalos com elevada frequência e intensidade. Dessa forma, os habitantes inseridos neste sistema popular reforçavam o seu festejo relativo a São João.

Outra crença mencionada que não está relacionada com a flora em si, mas sim com a geomorfologia local e seu coberto vegetal natural, isto é, o relato de uma pequena, mas surpreendente, história popular que envolve uma área natural designada por Mistérios Negros. Outrora, nesse local onde estava estabelecido um curral que servia para reunir o gado, conta-se que, durante uma ocasião, sem razão aparente, originou-se um fogo que consumiu não só a vegetação natural daquela zona, mas também todos os animais com exceção de um, isto é, aquele que estava destinado a ser sacrificado no culto do Espírito Santo.

\section{ORNAMENTAÇÃO}

A Hera (Hedera spp.) foi utlizada, até muito recentemente em épocas de festividades, sobretudo na decoração de salas onde o catecismo era instruído, nomeadamente, através das suas inflorescências (no caso da $H$. azorica), folhas e caules. Essa utilização demonstra não só um interesse pela beleza natural que a planta contém, mas também sua ligação com a doutrina religiosa.

A planta da espécie Laurus azorica (Louro) apresenta, igualmente, uma aplicação relativamente recente. Os ramos e as folhas dessa espécie eram utilizados, na época natalícia, para elaborar elementos decorativos e contextualizados na temporada. Para além da sua beleza reluzente, as folhas são simultaneamente coriáceas; uma característica muito apreciada, não só por conservar por mais tempo a sua 
coloração, mas também por se manterem fixas aos ramos durante a totalidade do período festivo.

A espécie Daucus azoricus é usada nos dias de hoje, com alguma frequência, na decoração, conforme menciona o informante $F$, pois a planta é muito usada na ornamentação de igrejas e habitações. A presença do seu comprido e vistoso escape floral, capaz de se manter num estado de vitalidade por um período significativo de tempo, confere-lhe, sobretudo depois de colocado em jarras, um admirável motivo decorativo.

\section{CONCLUSÃO}

Conclui-se que os dados coletados mostraram-se adequados e eficientes no levantamento de informação relativa à etnobotânica Açoriana. Com o implemento das entrevistas, conseguiu-se extrair um significativo volume de dados numa amostragem relativamente reduzida. Assim, foi possível confirmar que, das 52 utilizações totais registadas distribuídas por quatro classes de uso, 25 são citações novas. Em boa verdade, verificou-se que esses novos registos estão localizados no seio dos informantes pertencentes aos sistemas de vida rurais. Porém esse conjunto de pessoas com idade igual ou superior a 60 anos caminha, inevitavelmente, para a finalização do seu ciclo de vida transportando consigo os saberes tradicionais em direção à extinção. Essa circunstância é um indicador de alerta e o motor propulsor para a urgente recuperação desse património de natureza etnobotânica.

\section{REFERÊNCIAS}

ALEXIADES, Miguel N. Collecting ethnobotanical data: an introduction to basic concepts and techniques. In: ALEXIADES, Miguel N. (Ed.) Selected Guidelines for ethnobotanical research: a field manual [53-94]. New York: New York Botanical Gardens Press, 1996.
BALICK, Michael J.; COX, Paul A. Plants, people and culture - the science of ethnobotany. Scientific American Library, W. H. New York: Freeman Publishers, 1996.

BERNARD, Russel H. Research Methods in Cultural Anthropology. California, Newbury Park: Sage, 1988.

CAMERON, John. The Gaelic Names of Plants. Edinburgh: William Blackwood and Sons, 1883.

CARVALHO, Luís. M. Estudos de etnobotânica e botânica económica no Alentejo. 2006. Dissertação (Doutorado em Biologia, Sistemática e Morfologia) Faculdade de Ciências e Tecnologia da Universidade de Coimbra, Coimbra, 2006.

DIAS, Eduardo. Açores. In: Árvores e florestas de Portugal. A chegada dos portugueses às ilhas - o antes e o depois. Lisboa: Fundação Luso Americana para o Desenvolvimento e Liga para a Protecção da Natureza, 2007. p. 137-164.

DIAS, Eduardo; MENDES, Cândida; MELO, Cecília; BETTENCOURT, Maria. J. BARCELOS, Paulo. Lista de Referência da flora dos açores. Editor: Herbário da Universidade dos Açores (AZU). Departamento de Ciências Agrárias. Angra do Heroísmo: AZU, 2010.

FRUTUOSO, Gaspar. Saudades da Terra. Ponta Delgada: Instituto Cultural de Ponta Delgada, 1998. (Livro VI).

GASPAR, Jorge. As regiões Portuguesas. Lisboa: Direcção-Geral do Desenvolvimento Regional, 1993.

HARSHBERGER, William. The purposes of ethno-botany: the american antiquarian. In: BALICK, Michael J.; COX, Paul A. Plants, people and culture - the science of ethnobotany. Scientific American Library. New York: W. H. Freeman Publishers, 1996.

MAC COITIR, Niall; LANGRISHE, Grania. Irish wild plants - myths, legends and folklore. Ireland: [s.l.], 2006.

MARTINS, Francisco E. Ambientes açorianos da época dos descobrimentos à das viagens e emigração. Ponta Delgada: Signo, 1992.

MENDIOLA, Maria A. Etnobotânica. E.T.S.I.A. Universidade Politécnica de Madrid, 2005. (Apresentação em Power Point). 
NABHAN, Gary P. Gathering the Desert. Tucson: University of Arizona Press, 1985.

RAMOS, Accurcio G. Archipelago dos Açores História Natural. 2. ed. rev. Lisboa: Typografia Universal, 1871.

RIBEIRO, Luís S. Subsídios para um ensaio sobre a açorianidade. Angra do Heroísmo: Instituto Açoriano de Cultura, 1964.

SHÄFER, Hanno. Flora of the azores: a field guide. 2. ed. ampl. Weikersheim: Margraf Publishers, 2005.

WHYTE, William F. Interviewing in Field Research. In: BURGESS, Robert G. (Ed.). Field research: a sourcebook and field manual. London: George Allen \& Unwin, 1982. p. 111-122.

WICKENS, Gerald E. Economic Botany - Principles and Practices. Dordrecht Nederland: Kluwer Academic Press, 2001.

\section{Sobre os autores:}

Mauro Ponte: Universidade dos Açores. Departamento de Ciências Agrárias. Grupo de Ecologia Vegetal Aplicada. E-mail: pontemauro@gmail.com

Eduardo Dias: Universidade dos Açores. Centro de Biotecnologia dos Açores (CBA). E-mail: eduardo.mf.dias@uac.pt 